
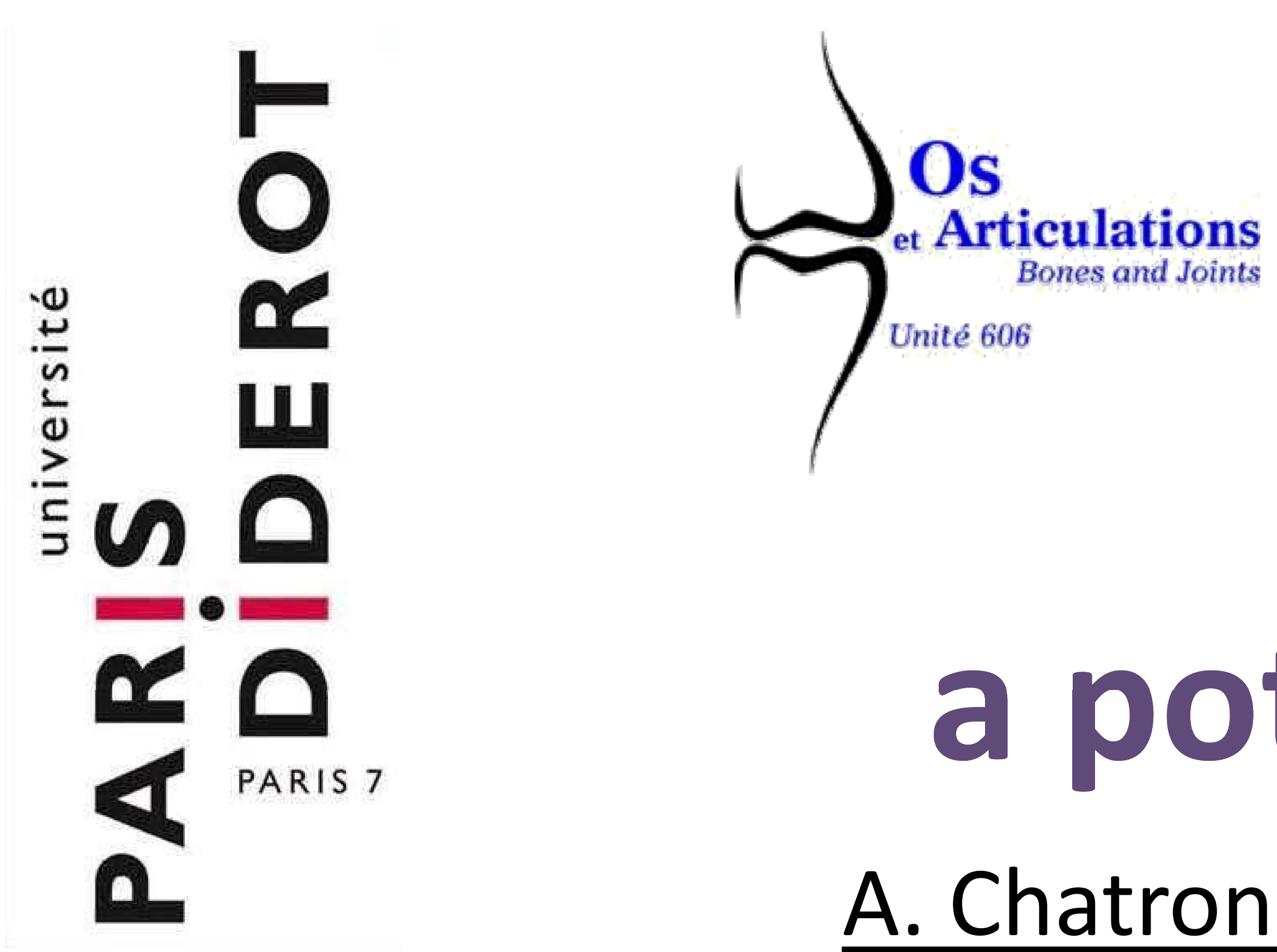

\title{
Can Adrenomedullin be
}

a potential Osteoarthritis treatment?

\author{
A. Chatron-Colliet, F. Velard, D. Côme, N. Hafsia, H. Lin , H. K. Ea, F. Lioté.
}

\section{BACKGROUND \& METHODS}

Chondrolysis, chondrocyte apoptosis and local inflammation are described to exacerbate osteoarthritis (OA) development. We therefore aimed to investigate the effects of adrenomedullin (AM) and its truncated peptide (22-52AM) on in vitro and in vivo OA models. Both have exhibited anti-apoptotic and anti-inflammatory properties in collagen-induced arthritis (CIA) in mice.

\section{IN VITRO METHODS}

Bovine articular chondrocytes (BACs)

IN VIVO METHODS

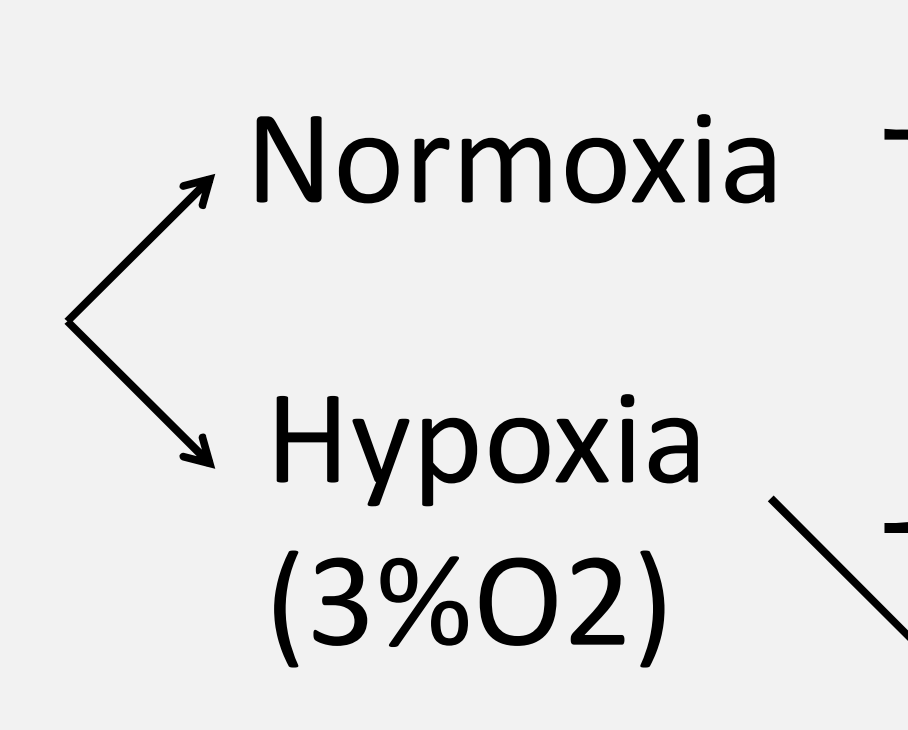

$(3 \% \mathrm{O} 2)$
$A M$ and receptor complex CLR/RAMP-2 protein levels

(1) (EIA, immunofluorescence).

CAMP production to assess the receptor functionnality

(2) Pro-apoptotic treatment (Fas-L) \pm AM

(3) Murine OA instability model $\triangle A M$ (meniscectomy)

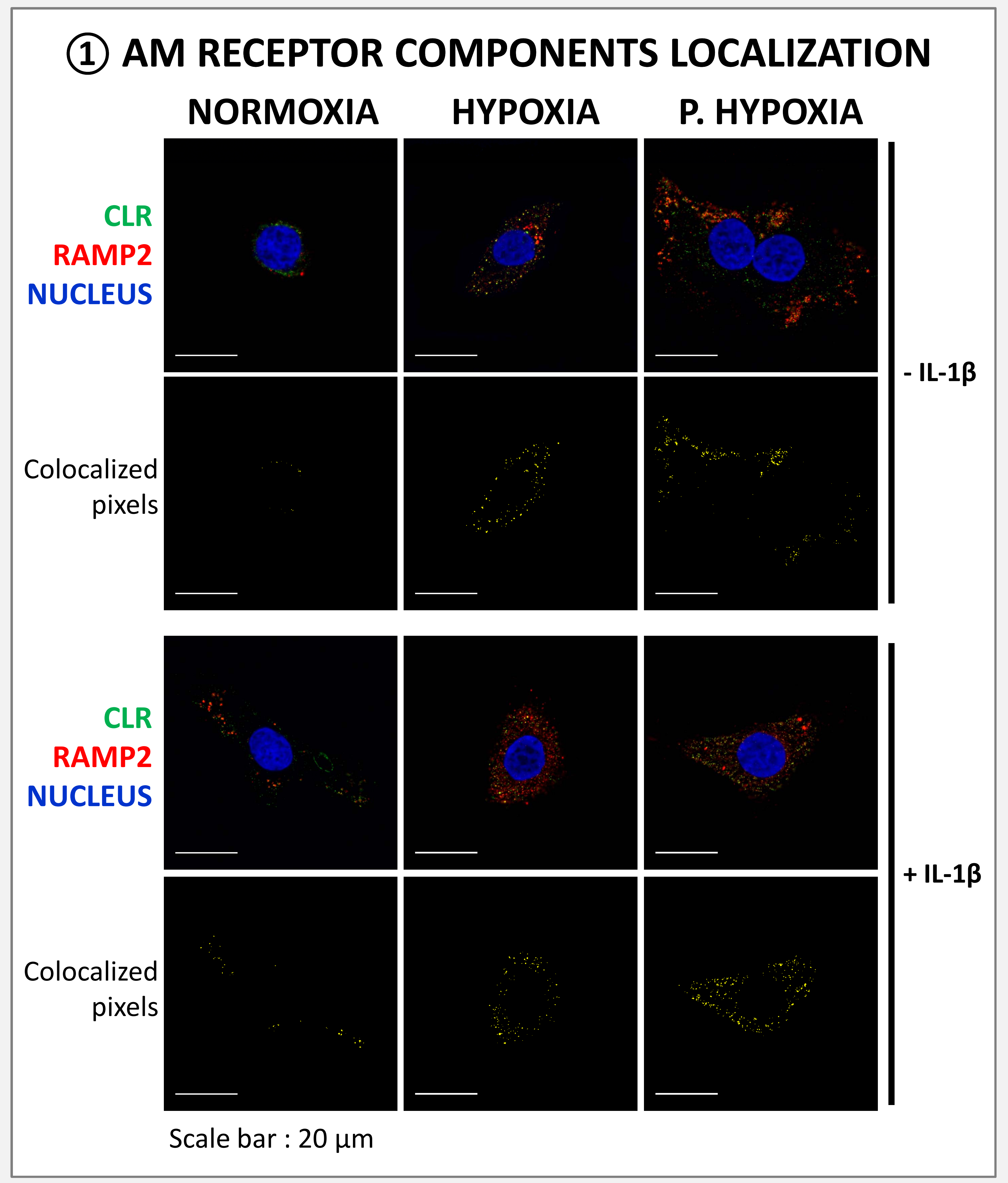

IN VITRO RESULTS

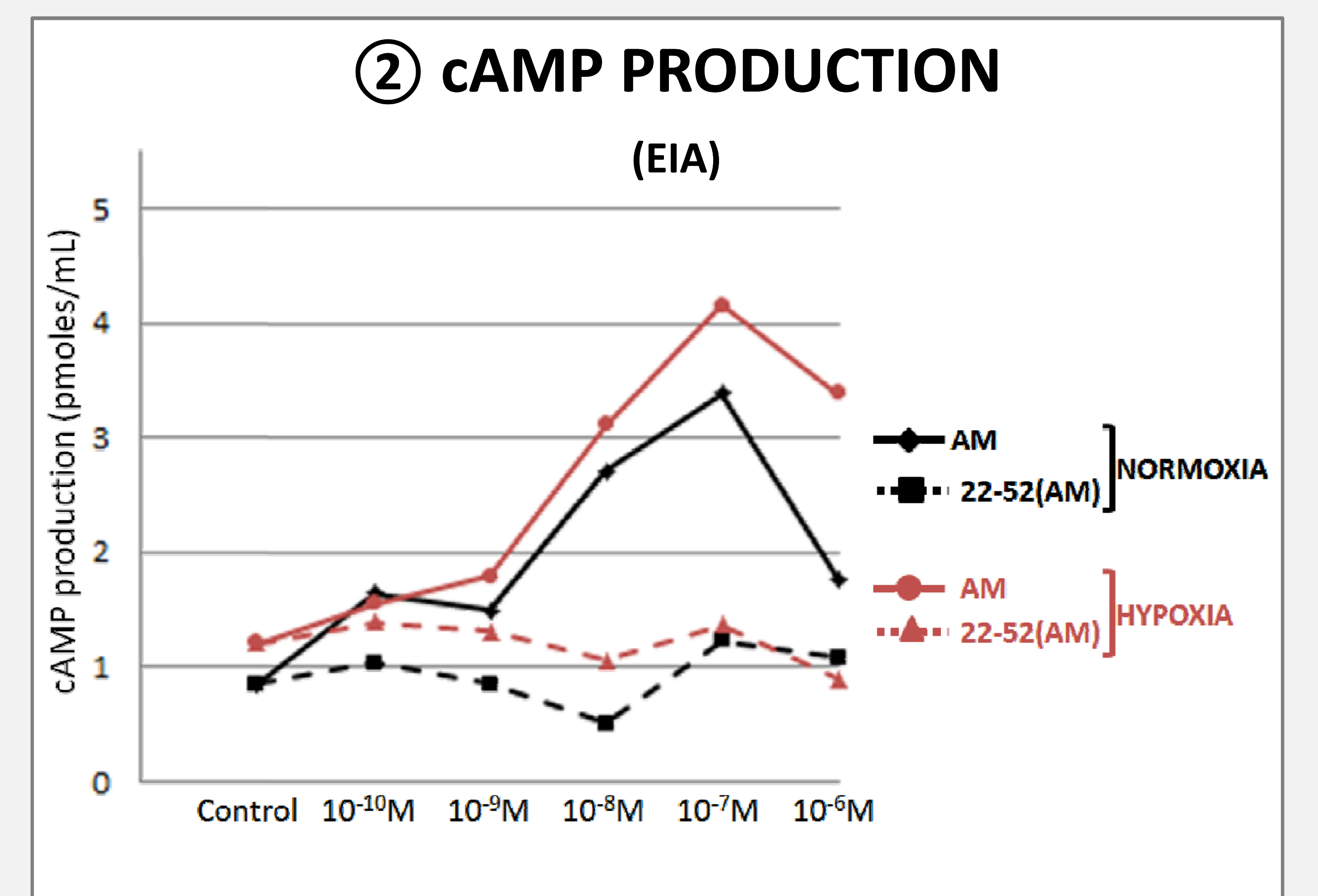

(1) AM and its receptor components are constitutively expressed in BACs. In physiological hypoxic environment, CLR-RAMP2 association is enhanced, as visualized by colocalized pixels. Moreover, inflammatory environment increases extensively this association. (2) IL-1 $\beta$ stimulation also induces an increased AM secretion in chondrocyte conditioned media and CAMP production suggests that AM receptor is functional, both in normoxia and hypoxia (3).

(4) Exogenous $\mathrm{AM}$ treatment $\left(10^{-6} \mathrm{M}\right)$ leads to a decreased caspase-3 activity, assuming AM could modulate chondrocyte apoptosis during $\mathrm{OA}$.

Given the $A M$ effects and the $A M$ receptor functionality, we address $A M$ as a preventive $O A$ treatment in vivo.

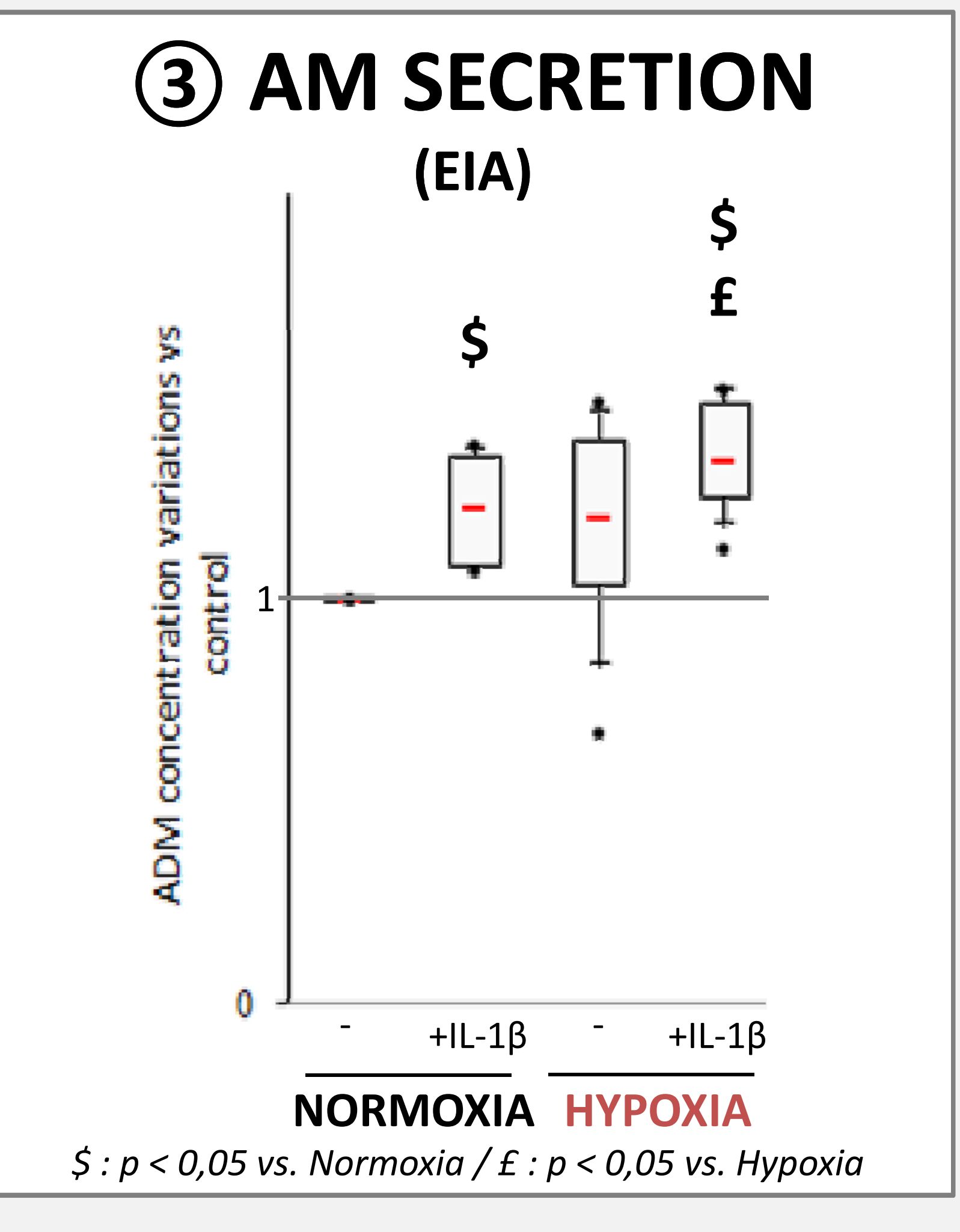

(4) CASPASE-3 ACTIVITY (specific fluorogenic substrate)

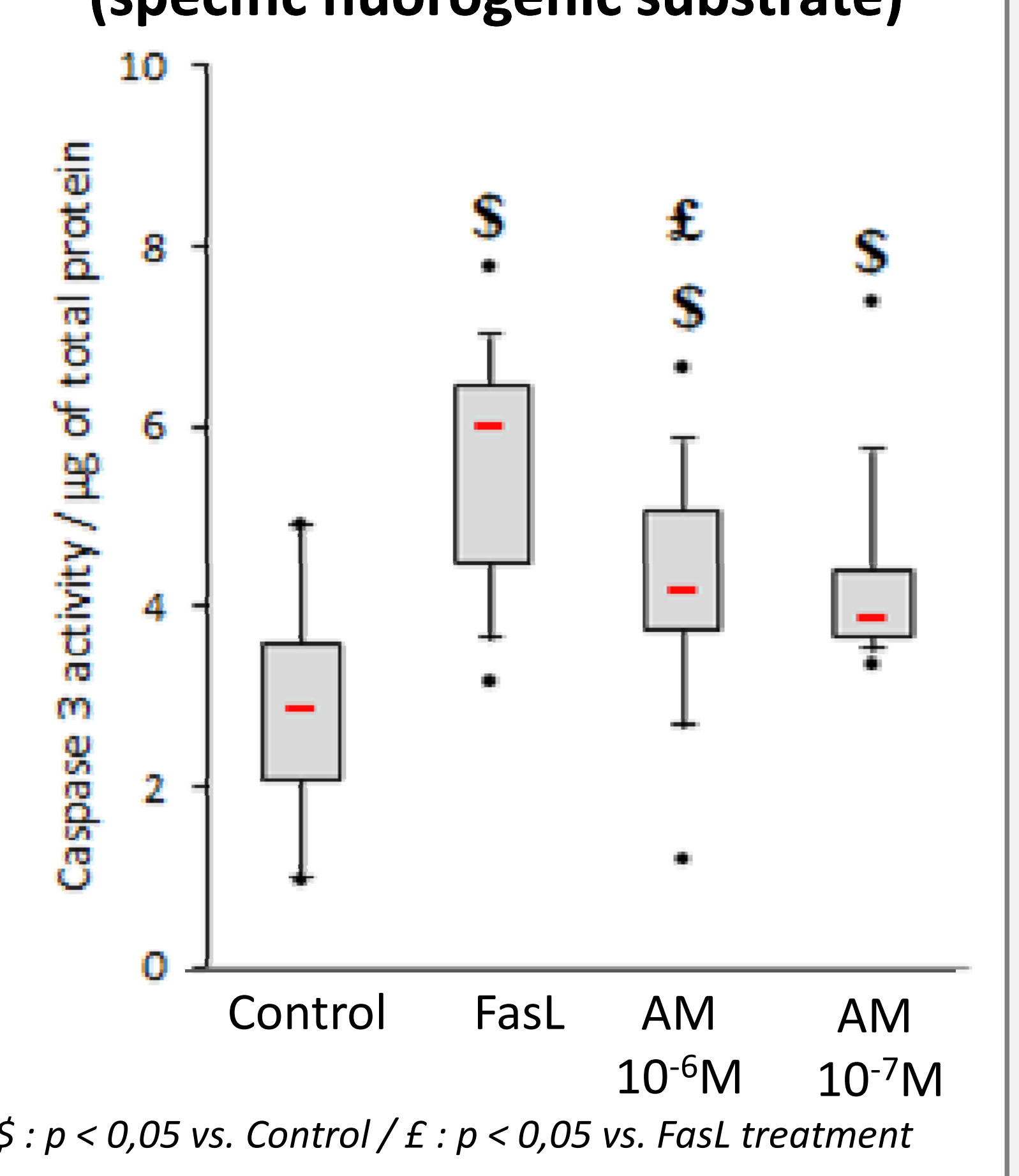

IN VIVO RESULTS

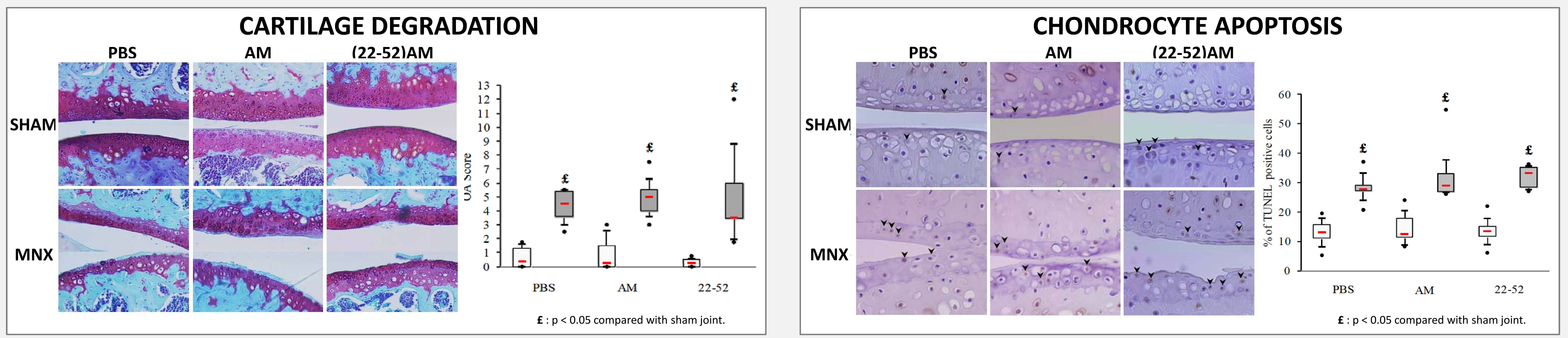

Neither AM nor (22-52)AM have a protective effect on apoptosis and chondrolysis.

\section{CONCLUSION}

In " physiological environment ", BACs were able to produce both ADM and functional receptor components. In addition, ADM treatment prevented FasL-induced apoptosis in hypoxia.

Contrary to our expectations based on the CIA model, ADM or its derived peptide 22-52ADM administered systemically did not disclose any effect on OA progression. Direct intra-articular effects of ADM might be investigated. 